ЕРОХИНА Оксана Валерьевна - кандидат политических наук, доцент департамента политологии факультета социальных наук и массовых коммуникаций Финансового университета при Правительстве РФ (125993, Россия, г. Москва, ГСП-3, Ленинградский пр-кт, 49; o.v.erokhina@ gmail.com)

\title{
ИНФОКОММУНИКАЦИОННЫЕ ТЕХНОЛОГИИ ДЛЯ УПРАВЛЕНИЯ ОБЩЕСТВЕННЫМ MHEHИЕМ
}

\begin{abstract}
Аннотация. Статья посвящена исследованию влияния информационных технологий на формирование общественного мнения. Модели восприятия информации в цифровом обществе отличаются нелинейностью и складываются в результате сетевых взаимодействий. Образы реальности, сформированные в массовом сознании участников сетевого общества, могут быть описаны в рамках междисциплинарного подхода, учитывающего и противопоставление древних архетипов “свой» - «чужой», и современную модель принятия решений, основанную на языке UML. Существующие цифровые средства контроля за распространением информации оказывают существенное влияние на формирование доминирующих социальных ценностей и установок. В статье рассматриваются технологии манипулирования общественным сознанием, а также два основных типа стратегий, используемых при построении социальной идентичности с использованием информационных технологий - отвержения (отчуждения) и эмпатии.
\end{abstract}

Ключевые слова: цифровое общество, технологии, формирования общественного мнения, стереотипы общественного сознания, социальные сети

И сточник информации создает информационное сообщение, которое достигает своей аудитории (общественности) через каналы взаимодействия, такие как СМИ, интернет-платформы, социальные сети и т.д. На пути распространения информации могут возникать препятствия, такие как барьер недоверия, вмешательство со стороны окружающей среды, искажение исходного сообщения и т.д. Общественное мнение трактуется как реакция целевой аудитории на полученное сообщение, и важно учитывать эффект обратной связи с отправителем сообщения, который может вызвать коррекцию исходного сообщения, воспринимаемого получателями информации неадекватно. Основную роль в реализации этих коммуникационных связей играет доверие или недоверие к конкретному источнику информации.

Развитие электронных средств массовой информации, сетевых коммуникаций и широкое внедрение цифровых стандартов формируют своего рода цифровое массовое сознание, в котором человек не стремится ничего знать, понимать или анализировать. Базовая потребность такого типа массового сознания заключается в простом сборе различной информации в сжатой, концентрированной форме, приоритет при этом отдается легкому для восприятия формату с визуальным или аудиосопровождением. Происходит слияние таких категорий, как знание, осознанность. Создание электронной инфраструктуры в органах государственной власти позволяет использовать новые каналы распространения информации и деятельности властных структур, что может способствовать как повышению доверия к властным структурам, так и монополизации каналов информации, злоупотреблению технологическими решениями в интересах бюрократии.

Сетевые технологии предоставляют дополнительные возможности для создания качественно новой модели социальной коммуникации, предполагаю- 
щей более или менее равноправный и максимально полный обмен информацией о процессах и явлениях, происходящих в обществе, экономике и политике. Изучение этих процессов должно быть комплексным, в связи с чем особенно востребован междисциплинарный подход. Один из возможных вариантов методологии - синтез общенаучных методов (классификация), методов политологии (бихевиоризм и неоинституционализм) и аналитической модели принятия решений, использующей инструменты лингвистики, включая выбор терминов (языковых выражений), которые используются для оценки альтернатив социального поведения.

Единого подхода к трактовке формирования общественного мнения не существует. Обобщая, можно утверждать, что для многих исследователей общественное мнение - это позиция одобрения или критики по наиболее важным вопросам и проблемам, связанным с такими фундаментальными понятиями, как развитие общества, поведение индивидов или их групп, которые выражают их отношение к установленным нормам или правилам, регулирующим социальные отношения. Классический подход У. Липпмана к проблемам формирования общественного мнения приобретает новую актуальность в цифровом обществе. Липпман указывал, что общественное мнение - это представление людей о себе, о других людях, об их потребностях, намерениях и отношениях, при этом на его формирование оказывают влияние в первую очередь стереотипы восприятия реальности, а не рациональные умозаключения [Липпман 2004]. В цифровую эпоху процесс формирования общественного мнения имеет свои особенности: люди все чаще обманывают себя рациональными объяснениями. Эти попытки самообмана связаны с такими когнитивными процессами, как получение и обработка информации. Наконец, создаются и широко распространяются «иллюзорные мнения», принадлежащие «другой реальности». В исследовательской среде остается актуальным мнение, согласно которому у значительной части общественности складываются субъективные, навязанные, искусственные представления о реальности, и эта тенденция, называемая исследователями «виртуализацией реальности», носит глобальный характер [Володенков 2018]. Также заслуживает внимания ставший авторитетным подход Э. Ноэль-Нойман, акцентирующей внимание на особенностях выражения индивидуального мнения и развивающей концепцию «спирали молчания» [Ноэль-Нойман 1996]. В рамках этого подхода общественное мнение выражает не только набор наиболее распространенных и часто стереотипных оценок и суждений, но и является инструментом давления по отношению к представителям меньшинства, имеющим отличную от «мейнстрима» позицию и вынужденным ориентироваться на приемлемые для большинства паттерны социального поведения.

С учетом разнообразия подходов к изучению общественного мнения особый интерес представляет возможность применения междисциплинарных методов; одним из самых востребованных выступает моделирование. Рассмотрим подробнее одно из перспективных направлений для исследования механизмов формирования общественного мнения - модель принятия решений на основе языка $U M L$.

Важно отметить, что модели восприятия информации в цифровом обществе нелинейны: ключевую роль в обмене информацией играют социальные сети, в которых взаимодействие носит разнонаправленный характер. Образы реальности, сформированные в массовом сознании, могут быть описаны определенным устойчивым набором терминов, и эта задача успешно решается информатикой с использованием языка $U M L$. В этом случае, как показано в работах ряда исследователей [Гайдамака и др. 2019], продуктивно использовать 
аналитическую модель принятия решений, использующую инструментарий лингвистики.

Цифровые технологии выступают наиболее эффективным способом реализации сетевых взаимодействий, при этом основной задачей выступает сбор разнообразных точек зрения и формирование «среднего» мнения, а не поиск компромиссного решения, которое отвечало бы общим интересам. Для определения «среднего» мнения весьма востребованы методы информатики, в т.Ч. аналитическая модель принятия решений на основе языка $U M L$. Речь идет о выборе терминов (языковых выражений), используемых для оценки альтернатив социального поведения или вариантов решений той или иной проблемы. На основе базового набора терминов формируются рейтинги предпочтений и поведения, а использование индексов позволяет ранжировать термины, которые по умолчанию являются одинаково информативными. «Среднее мнение» в данном случае носит экспертный характер: каждый эксперт выбирает свой собственный набор базовых терминов, исходя из того мнения, которое он высказывает, обладая определенной (не общей) информационной базой. В этом случае процесс оценки вариантов социального поведения и принятия решений можно представить в виде следующей модели.

Если символ $и$ является символом эксперта, а $y$ - альтернативой принимаемому решению, то при наличии определенного набора экспертов можно получить множество оценок и мнений, среди которых «среднее» может быть найдено с помощью компьютерной программы по следующему алгоритму. $U=\left\{u_{1}, \ldots u_{k}\right\}-$ множество экспертов, такое что $|U|=K<\infty$, где $K-$ число экспертов, а $Y=\left\{y_{1}, \ldots, y_{M}\right\}-$ множество альтернатив, таких что $|Y|=M<\infty$, где $M$ - число альтернатив. $Y_{k} \subseteq Y$ - подмножество альтернатив, выбранных экспертом $u_{k}, u_{k} \in U$. Значение предпочтения эксперта $U_{y}$ альтернативе $y_{i}$ по отношению к альтернативе $y_{j}$ обозначается переменной $p_{i j}(k), i=j, y_{i}, y_{j} \in X$. Применение описанной $U M L$-модели при анализе процесса коллективного принятия решений обеспечивает классификацию альтернативных сценариев от наиболее благоприятного до наименее благоприятного. Методы информатики для анализа социально-политических процессов весьма перспективны в связи с возможностью быстро собирать и оперативно обрабатывать большие объемы данных, при этом сокращая издержки на проведение исследования (по сравнению, например, с более привычными социологическими методами). Помимо получения «среднего» экспертного мнения (набор усредненных оценок может быть представлен в виде матрицы), можно подобным образом на основе ряда переменных оценивать эффективность принимаемых решений (эффективность процесса группового принятия решений оценивается с помощью коэффициента участия). Ограничения в процессе применения $U M L$-модели связаны с необходимостью обеспечения «консенсуса по базовым ценностям» среди экспертов, иначе говоря, при выборе альтернатив участники исследования должны исходить из некоторых общих предпосылок для получения достоверного результата.

Отдельным направлением изучения процесса формирования общественного мнения в цифровом обществе выступает исследование технологий манипуляции информацией. Специфика этого процесса в «цифровых» условиях обусловлена стремительным развитием интернет-технологий и сервисов, виртуализацией медийной сферы. Медиа становятся инструментом, позволяющим контролировать поведение и действия значительного числа людей, влиять на их мнение об окружающем мире и конкретных фактах, событиях, явлениях и процессах социальной реальности. Для этих целей используются технологии манипулирования массовым сознанием. Под манипуляцией сознанием можно 
понимать скрытое, невидимое воздействие на психику, которое в основном идет во вред тем лицам, на которых оно направлено [Веснин 2016]. Целью такого воздействия является контроль над манипулируемыми лицами и контроль над их мыслями (сознанием) и поведением (действиями).

Одна из самых известных технологий формирования общественного мнения, основанная на применении манипуляции в долгосрочной (стратегической) перспективе, была описана американским общественным деятелем Дж. Овертоном; исследователи его идей сформулировали понятие «окна Овертона» уже после его смерти [Якоба 2019]. Суть этой технологии заключается в том, что общественное мнение имеет пределы терпения, в рамках которых можно выполнять определенные пошаговые действия по перестройке сознания людей. Если на первом этапе публичное обсуждение определенной темы немыслимо, то, например, его принимают ученые, которые по своему профессиональному долгу обязаны исследовать какие-либо проблемы. На следующем этапе название этого явления меняется, часто даже несколько раз, чтобы полностью запутать обычных людей и стереть его истинный смысл. На третьем этапе эта проблема становится предметом активного обсуждения в средствах массовой информации.

Широкие возможности информационных технологий для манипулирования общественным сознанием привели к такому явлению социальных сетей, как фейковые новости - не соответствующая действительности информация, которая, тем не менее, имеет высокую степень тиражирования. Особенностью фейковых новостей является целенаправленное искажение социально значимых сообщений, содержание которых может изменить жизнь не только отдельного человека, но и всей страны в целом. Появление феномена тиражирования ложных новостей в первую очередь связано с активным развитием информационной среды и повышением ее интерактивности. Эти факторы приводят к снижению надежности контента, генерируемого пользователями, и, как следствие, к увеличению числа фейков. Чаще всего эти факторы формируются на основе наиболее актуальных событий повестки дня, которые затрагивают максимальное число граждан, поэтому бесконтрольное распространение такой недостоверной информации может привести к целому ряду разрушительных последствий, в т.ч. нанести ущерб экономическим интересам граждан, их жизни и здоровью. Отмечается заведомо ложный, а иногда и провокационный контент, распространяемый исключительно ради повышения рейтингов, численности аудиторий и других рыночных аспектов интернетпространства. В попытках монетизировать информационную повестку, возникающую в таких случаях, авторы фейковых новостей редко задумываются о том, к каким последствиям приведут эти действия [Каминская 2019].

Использование механизма манипулирования общественным мнением позволяет не только актуализировать проблему поиска и усвоения общественно значимой информации, но и искажать имеющуюся информацию с целью воздействия на сознание групп людей. Инфокоммуникационные технологии в этом качестве весьма эффективны: средства массовой информации и социальные сети способны в значительной степени контролировать и определять ценности общества, представляя доминирующие социальные ценности и оказывая влияние в т.ч. на политическое поведение граждан [Пырма 2019].

Важно обратить внимание на вопрос управления процессом формирования мнений в социальных сетях. Речь идет о целенаправленном воздействии на аудиторию с целью выработки определенных моделей социального поведения, при этом представления участников сети (агентов) определяются несколькими базовыми переменными. К ним относятся мнение, доверие и репутация. 
Существует ряд моделей изучения процесса влияния на групповое восприятие информации и управление мнениями в социальных сетях, которые подробно изучаются с точки зрения применения математических методов [Губанов, Новиков, Чхартишвили 2010]. Авторы математически доказывают, что чем выше репутация агента, управляющего потоком информации, тем больше он может влиять на формирование окончательной картины того или иного явления среди участников социальной сети.

Таким образом, необходимо учитывать как высокую значимость репутации агента (источника информации), который стремится контролировать поведение участников коммуникации в интернет-пространстве, так и мнения, которые уже есть у аудитории. Целенаправленное применение коммуникационных технологий властными структурами способно обеспечить эффективное продвижение даже изначально непопулярных решений [Ракчинская 2018].

Цифровая реальность основана на быстрой передаче информации, быстром движении информации. Готово ли общество к этому? Исследования показывают, что восприятие информации в цифровую эпоху значительно меняется. Информационные технологии активно влияют на коммуникации в сфере взаимодействия власти с общественностью. Ключевую роль в обмене информацией играют социальные сети, в рамках которых взаимодействие акторов носит разнонаправленный характер. Образы реальности, сформированные в массовом сознании, могут быть описаны как с помощью методов политического и дискурс-анализа, так и с помощью модели принятия решений, основанной на синтезе информатики и лингвистики.

\section{Список литературы}

Веснин В. А. 2016. Технологии формирования общественного мнения. Власть. № 6. С. 70-74.

Володенков С.В. 2018. Роль информационно-коммуникационных технологий в современной политике. - Научный ежегодник Института философии и права Уральского отделения РАН. Т. 18(2). С. 69-86.

Гайдамака А., Чухно Н., Чухно О., Самуйлов К., Шоргин С. 2019. Формализация метода ранжирования альтернатив для процесса принятия групповых решений при анализе социальных сетей. - Информатика и вычислительная техника. Т. 13. № 3. С. 63-71.

Губанов Д., Новиков Д., Чхартишвили А. 2010. Социальные сети: модели информационного влияния, управления и конфронтации. М.: Физматлит. 228 с.

Каминская Т.Л. 2019. Политические медиатексты и проблема доверия: современные вызовы. - Гуманитарные науки. Вестник Финансового университета. № 9(5). С. 15-21.

Липпман У. 2004. Общественное мнение (пер. с англ. Т.В. Барчуновой). М.: Институт Фонда «Общественное мнение». 384 с.

Ноэль-Нойман Э. 1996. Общественное мнение. Открытие спирали молчания (пер. с нем. и предисл. Н.С. Мансурова). М.: Весь Мир. 352 с.

Пырма Р.В. 2019. Влияние цифровых коммуникаций на политическое участие. - Гуманитарные науки. Вестник Финансового университета. № 9(4). C. 63-69.

Ракчинская Н.В. 2018. Продвижение непопулярных политических решений как технология манипулирования общественным мнением. -Гуманитарные науки. Вестник Финансового университета. № 8(4). С. 110-115.

Якоба И.А. 2019. Деконструкция технологии «Окно Овертона» в американском медийном дискурсе. - Вестник Череповецкого государственного универсиmema. № 5(92). С. 175-185. 
EROKHINA Oksana Valer'evna, Cand.Sci. (Pol.Sci.), Associate Professor of the Department of Political Science, Faculty of Social Sciences and Mass Communications, Financial University under the Government of the Russian Federation (49 Leningradsky Ave, GSP-3, Moscow, Russia, 1259930; o.v.erokhina@gmail.com)

\title{
INFOCOMMUNICATION TECHNOLOGIES FOR PUBLIC OPINION MANIPULATING
}

\begin{abstract}
The article is devoted to the study of the influence of information technologies on the formation of public opinion. Models of information perception in a digital society are characterized by non-linearity and are formed as a result of network interactions. The images of reality formed in the mass consciousness of the participants of the network society can be described within the framework of an interdisciplinary approach that takes into account both the opposition of the ancient archetypes of "friend" and "stranger», and the modern decision-making model based on the UML language. The existing digital means of controlling the dissemination of information have a significant impact on the formation of dominant social values and attitudes. The article discusses the technologies of manipulating public consciousness, as well as two main types of strategies used in building social identity using information technologies: rejection (alienation) and empathy. The study of the mechanisms of rejection and empathy formation in the process of social identity formation is useful for developing new practices of coordinating interests for the stability of democratic institutions in the new digital reality.
\end{abstract}

Keywords: digital society, technologies of public opinion formation, stereotypes of public consciousness, social networks

КОЖЕВНИКОВ Алексей Михайлович - преподаватель кафедры информационного обеспечения Военного университета (123001, Россия, г. Москва, ул. Большая Садовая, 14; reporterkorg@yandex.ru)

\section{ИНТЕРНЕТ-КОММУНИКАЦИОННЫЕ ФАКТОРЫ ЦЕННОСТНЫХ ОРИЕНТАЦИЙ РОССИЙСКОЙ МОЛОДЕЖИ}

Аннотация. В статье рассматривается актуальная тема воздействия интернет-коммуникаций на формирование ценностных ориентаций современной молодежи. Исследовательское внимание уделено раскрытию групп факторов, имеющих отношение к теме сетевого влияния на компоненты ценностной ориентации. В статье приводятся результаты авторского исследования, проведенного в университетах Москвы.

Ключевые слова: интернет-коммуникационные факторы, ценностные ориентации, молодежь

Сегодня формирование жизненных ценностей является одной из самых обсуждаемых и в то же время важнейших проблем в социологии. Само определение жизненных ценностей утверждает, что это совокупность установок, индивидуально сформированных в процессе социализации индивида. Развитие человечества напрямую связано с тем, какие взгляды преследуют и продвигают в обществе. До появления онлайн-коммуникаций обмен информацией был крайне ограничен многими факторами, такими как скорость ее получения, отсутствие разнообразных носителей информации, проблематичность получения актуальной информации [Кожевников, Масликов 2020а: 3298].

С развитием информационных технологий общение и обмен своими взглядами точками зрения и идеалами стал невероятно простым. Естественно, что с 